\title{
Lift of cheek and neck: technical notes
}

\author{
Maurice Yves Mommaerts \\ European Face Centre, Universitair Ziekenhuis Brussel, Laarbeeklaan 101, 1090 Brussels, Belgium.
}

Address for correspondence: Prof. Maurice Yves Mommaerts, European Face Centre, Universitair Ziekenhuis Brussel, Laarbeeklaan 101, 1090 Brussels, Belgium. E-mail: maurice.mommaerts@uzbrussel.be

\section{INTRODUCTION}

Because alternatives exist for the full facelift (rhytidectomy), this procedure has become less popular overtime. In the past, forehead wrinkles were addressed with coronal ${ }^{[1,2]}$ and endoscopically assisted forehead lift $^{[3]}$ procedures. Today, botulinum toxin and hyaluronic acid fillers are used for this purpose because they are more effective and result in less downtime. Lateral brow sag can be corrected by using the Fogli $^{[4]}$ and Knize $^{[5]}$ browlift techniques, Endotine ${ }^{\circledR}$ browlift ${ }^{[6]}$ or sub-brow fat augmentation..$^{7]}$ The pretrichial incision is occasionally chosen, typically in facial feminization surgery, which includes supraorbital rim contouring and scalp advancement. ${ }^{[8]}$ Although indications for facelift surgery remain, they are limited. A more recent approach to restoring a youthful appearance to the midface involves volume augmentation, although this is questionable. ${ }^{[9]}$ Facial aging is thought to be primarily due to gravitational sagging because of the loss of collagenous support [Figure 1]; however, fillers provide more predictable results than lifting in this area. Furthermore, hyaluronic acid fillers are more predictable than micro fat grafting ${ }^{[10]}$ and are safer to use around the eyes. ${ }^{[1]}$ The lifting of tissues is more useful in the lower face (caudal extension of nasolabial folds and grooves, labiomental folds and grooves and jowls disrupting the jaw line) and neck (platysmal bands, skin excess). Hence, "cheek and neck lift" or "buccocervical lift" may be more appropriate terms for this type of procedure.

This article describes important features of facelift surgery as performed by the author. All patients involved in this article agreed to have their facial pictures published and signed the consent form. The proper sequence of steps is explained in the last section.

\section{Video Available on: www.parjournal.net}

\begin{tabular}{|l|l|}
\hline \multicolumn{2}{|c|}{ Access this article online } \\
\hline Quick Response Code: & Website: \\
\cline { 1 - 2 } & www.parjournal.net \\
\cline { 1 - 2 } & \\
\hline & \\
\hline
\end{tabular}

\section{MINIMAL SEDATION}

For all patients, reduction of anxiety and mild hypnosis are achieved with the oral administration of $1 \mathrm{mg}$ lorazepam, along with the $100 \mathrm{mg}$ of diclofenac, $1 \mathrm{~g}$ of paracetamol, $2 \mathrm{~g}$ of penicillin and $32 \mathrm{mg}$ of methylprednisolone given $1 \mathrm{~h}$ prior to the procedure. Lorazepam has a half-life of 9-16 $h,{ }^{[12]}$ which helps the patient to remain calm and normotensive postoperatively. Because pain occurs only with injection of the local anesthetic intravenously solution along the skin incision line, midazolam is given 2 min prior to the administration of local anesthetic for those patients who are anxious IV or agitated; oriented and calm patients may not require sedation. Midazolam is given by slow intravenous injection, starting with a test dose of $0.1 \mathrm{mg}$ and slowly delivering a total dose of 2-6 mg (depending on body weight) over $2 \mathrm{~min}$. During this time the skin is marked for the incision and prepping and draping are performed. The half-life of midazolam is 2-6 h. ${ }^{[13]}$ The goal is to achieve a co-operative, oriented and calm state (level 2 on the Ramsey Scale of Sedation). ${ }^{[14]}$ The patient should still be able to respond normally to verbal stimuli (i.e. minimal sedation on the American Society of Anesthesiologists scale of sedation); however, if moderate or conscious sedation is reached (i.e. purposeful response to verbal/tactile stimulation), this state will not last longer than $20 \mathrm{~min}$.

\section{INFILTRATION ANESTHESIA USING THE WHITACRE SPINAL NEEDLE}

The aim is to numb the area and provide a bloodless surgical field, defined by the marked dissection area, including the skin and superficial muscular aponeurotic

This is an open access article distributed under the terms of the Creative Commons Attribution-NonCommercial-ShareAlike 3.0 License, which allows others to remix, tweak, and build upon the work non-commercially, as long as the author is credited and the new creations are licensed under the identical terms.

For reprints contact: reprints@medknow.com

How to cite this article: Mommaerts MY. Lift of cheek and neck: technical notes. Plast Aesthet Res 2015;2:301-8.

Received: 30-05-2015; Accepted: 08-09-2015 
system (SMAS). The first step is to achieve a superficial, cephalad cervical plexus block, aiming for the lesser occipital nerve, great auricular nerve and transverse cervical nerve rather than the inferiorly running nerves of the punctum nervosum. An aliquot of 3\% lidocaine (one $1.8 \mathrm{~mL}$ carpule) with norepinephrine $(1: 100,000)$ is placed at the punctum nervosum, which is located at the posterior aspect of the sternocleidomastoid (SCM) muscle, midway between the mastoid process and the transverse process of C6 [Figure 2]. The second step is to infiltrate the periauricular incision line using 2 carpules of lidocaine and a serial puncture technique. The third step involves the infiltration of the dissection area using a Whitacre epidural cannula and the super wet technique with a modified Klein solution consisting of one $20 \mathrm{~mL}$ vial of lidocaine $(2 \%)$ with epinephrine $(1: 100,000)$ and two vials of $0.9 \%$ sodium chloride (normal saline). ${ }^{[15]}$ The 25-gauge 3.5 inch Whitacre spinal needle (Becton, Dickinson and Company, NJ, USA) has a pencil tip and lateral opening, which spreads the subcutaneous tissues without cutting nerves and vessels. With a little pressure, it is inserted into the area infiltrated in step 2. The area can then be anesthetized painlessly by slowly sliding the cannula in the subcutaneous fat plane, continuously delivering the small amounts of the anesthetic solution [Video 1].

Whereas the tumescent technique uses a large volume of dilute solution to stretch the skin taut, the super wet technique injects less than half the volume required for the tumescent technique, $40 \mathrm{~mL}$ suffices to infiltrate both sides.

\section{MICRO-LIPOSUCTION}

As we age, the loss of fibrous support, endocrine changes, a sedentary life style and excess caloric intake result in fat pockets in the cheek and the anterior neck becoming more voluminous and delineated. Disruption of the jaw line by jowling is often the first sign that leads patients to consider a cosmetic procedure, and submental lipodystrophy is hereditary in some individuals. Because a skin-only facelift cannot alter these signs of aging, submental liposuction is carried out prior to the lateral work, requiring another $20 \mathrm{~mL}$ of simplified Klein solution. Central lipodystrophy is accessed by a 2 -mm incision with a number 11 blade anterior to the submental crease. A Becker grater round cannula (2.7 mm diameter, Wells Johnson Company, Tucson, AZ, USA) [Figure 3] is connected to a $10 \mathrm{~mL}$ disposable syringe with a luer lock and introduced without suction to dissect the subcutaneous plane at the supraplatysmal level. It is easy to inadvertently enter the subplatysmal plane, leading to disruption of the capsule of the submandibular gland with subsequent ptosis or injury to the marginal branch of the facial nerve. After determining the appropriate plane, the syringe plunger is withdrawn to create a $2-\mathrm{mL}$ space. Just posterior to the central stab incision, a cannula with an open tip is used to maintain negative pressure in the syringe, with the tip close to the exit site. Rapid movements are required [Video 2].

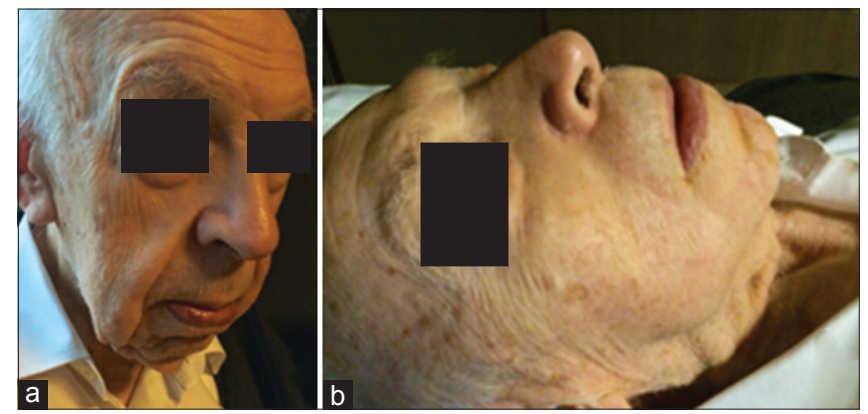

Figure 1: Effect of gravity (position) on the facial soft tissues of an 86-year-old man in upright (a) and prone (b) positions; the photo in (b) was rotated $90^{\circ}$ for comparison with the photo in (a) to shows the effects of gravity on the midface, revealing that the aged appearance results not only from fat atrophy but also from gravity

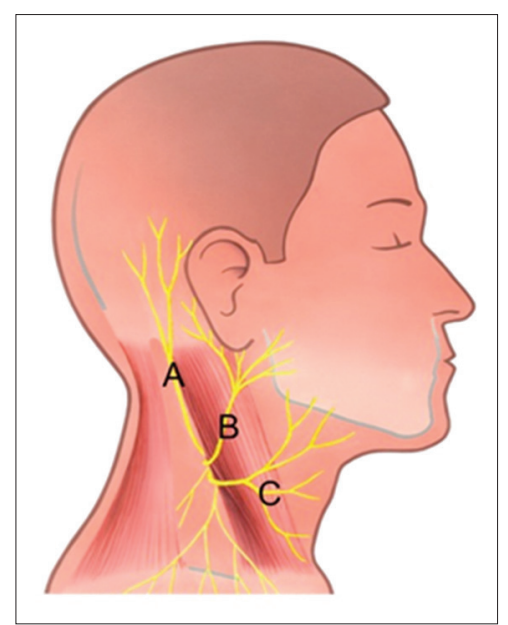

Figure 2: Punctum nervosum with the branches. A: lesser occipital nerve; $\mathrm{B}$ : great auricular nerve; and C: transverse cervical nerve

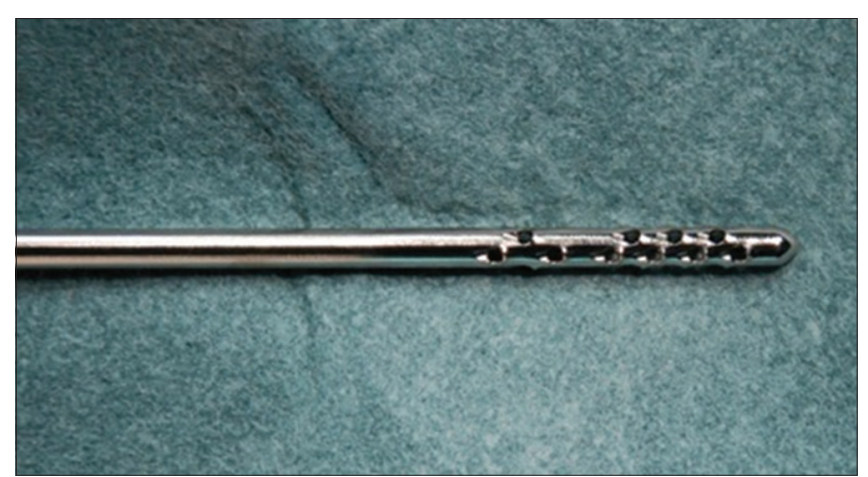

Figure 3: A $2.7 \mathrm{~mm}$ Becker grater round cannula with multiple perforations (1 $\mathrm{mm}$ diameter)

Surgical removal of the jowl fat is essential for the lifting procedure. This may be performed by Metzenbaum scissors or by open liposuction with a Becker grater cannula, after elevating the skin flap [Figure 4]. However, closed liposuction through a 2-mm stab incision anterior to the earlobe can be used to avoid irregularities, hematomas and damage to the marginal branch of cranial nerve VII. Counter pressure is important, but also leaving a layer of fat on the undersurface of the dermis [Video 3].

\section{BAKER SMASECTOMY}

Traction on low suspension sutures provides a strong 
lifting effect to the neck compared to the high suspension of the SMAS flap used in a classic facelift. The disadvantage is that the purse string formed by plication of the SMAS can result in preauricular fullness in heavier patients. The lateral SMAS ectomy ${ }^{16]}$ offers a solution [Figure 5]. Excision of a portion of the SMAS overlying the anterior section of the parotid gland secures the mobile anterior SMAS to the fixed portion of the superficial fascia. The long axis of the lentoid incision is oriented such that the vectors of elevation following SMAS closure lie perpendicular to the nasolabial fold. This procedure avoids extensive SMAS flap dissection and elevation, which risks damage to the buccal branches of cranial nerve VII and tearing of the flap. In addition, lateral bulkiness is addressed.

\section{DANGER ZONES}

Because the SMAS and platysma muscle are not elevated, and liposuction is preferred to lipectomy, there is no risk of injury to branches of the facial nerve. However, injury to the great auricular nerve can lead to a painful neuroma. Dissection of the skin flap overlying the mastoid fascia and under the earlobe should be confined to the reticular layer of the dermis. Sensation in the earlobe should return to normal or near normal by one week. In case of neuralgia, repeated injections with ropivacaine or betamethasone may be helpful.

Laceration of the facial vein [Figure 6] leads to bleeding, ecchymosis and sometimes hematoma. Coagula can lead to oozing because of fibrinolysis. They are difficult to remove because dissection of the tissue planes is required; following evacuation the epidermis appears lax and pigmented for a prolonged period. Vein laceration can be prevented by using Metzenbaum scissors, keeping the tips parallel to the skin surface and remaining in contact with the reticular dermis. Retrieving the vein stump after complete resection can be difficult as it retracts, and for this reason, bipolar coagulation is used. The vein may also be punctured by a suture needle when weaving the loops (the weaving is done with a sertix suture: suture and needle).

\section{ALPHA AND OMEGA OF THE INCISION, CURVES, DOG-EARS}

Scalp extension to create sideburns, which are beveled as described by Frechet ${ }^{[17]}$ and scalloped as described by Camirand and Doucet, ${ }^{[18]}$ opens the superior tunnel in a manner that allows for suspension of the SMAS to the temporalis fascia [Figure 7a]. ${ }^{[19]}$ However, the result is a visible scar that cannot be erased [Figure 7b]. Attempts at correction will thin the sideburn hair and make the area less attractive. As mentioned in section one, the approach to the midface involves volume augmentation rather than lifting. The temporal extension does not improve the result.

The author recommends that the incision begins where the anterior helix separates from the preauricular skin and becomes the superior helix of the pinna. Depending

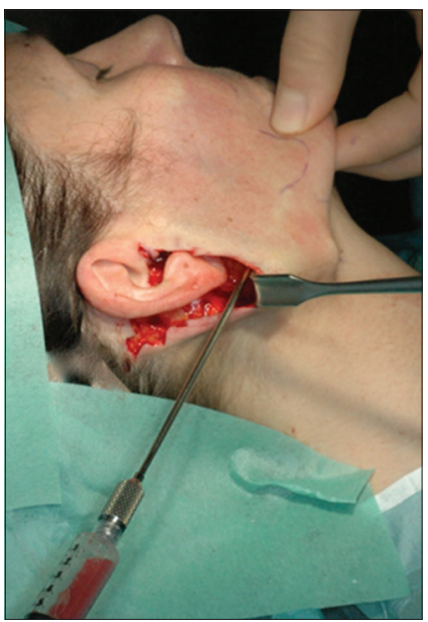

Figure 4: Open-sky liposuction of the jowls
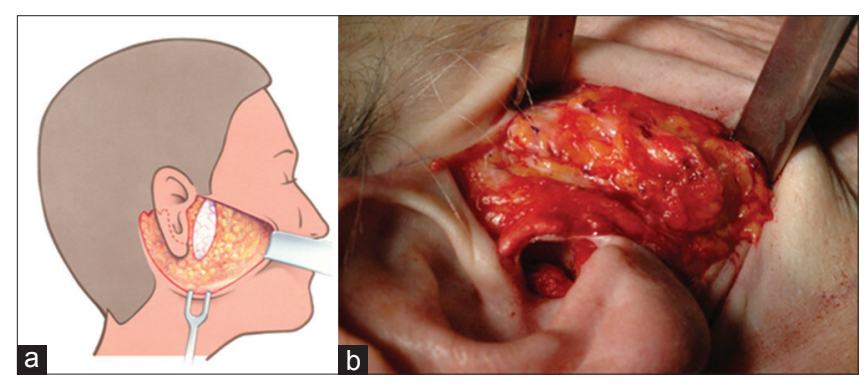

Figure 5: Lateral SMAS ectomy, as described by Baker $(2,000)$. (a) Schematic diagram; (b) intraoperative photograph. Resorbable 4-0 Vicryl placed after resection

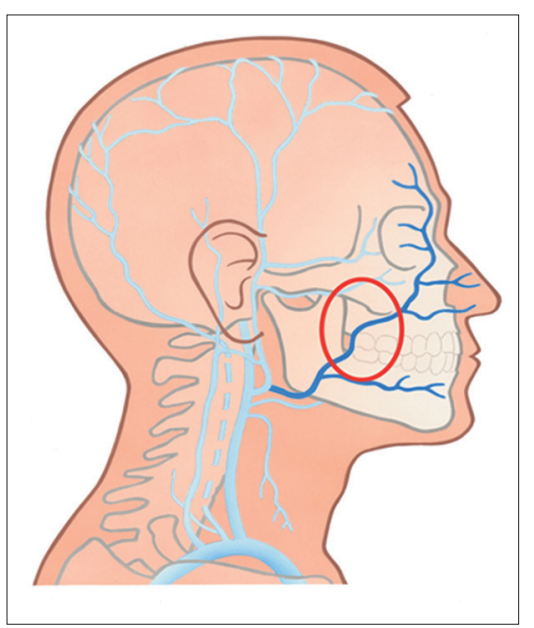

Figure 6: The facial vein (darker blue) at the edge of the dissection area (red oval) is difficult to visualize and may, therefore, be accidentally nicked, resulting in bleeding

upon the vector, the amount of lift and skin elasticity, the dog-ear may be small or substantial. Cephalad undermining is attempted first and is generally effective. Otherwise, an infra-sideburn incision, as described by Knize [Figure 8], ${ }^{[5,20]}$ or a $1-\mathrm{cm}$ hockey stick extension can be used while keeping the scar hidden behind the sideburn.

The incision descends in front of the inferior crus and at the inner aspect of the tragus [Video 4]. The cartilage should not be notched as this will be visible after healing. The incision runs just anterior to the earlobe and curves around its attachment. After bipolar coagulation, the 
superior subcutaneous tunnel is prepared. The incision then runs behind the pinna in the cephalad direction to the conchal cartilage; the scar will contract and be pulled down into the groove. If the incision is inadvertently placed in the auriculomastoid groove, the scar will be pulled into the visible mastoid area. The incision becomes horizontal at the level of the external auditory canal and then is scalloped, curving cephalad [Figure 9]. It should generally not extend into the occipital hairline, but if it does, it curves caudally again. The scalloped incision is beveled according to the method of Frechet, in the area of hair-bearing skin. The scalloped incision developed by Camirand and Doucet ${ }^{[18]}$ aids tremendously in dealing with the retroauricular dog-ear. After removing excess skin, the straight long excision edge of the flap is sutured into the scalloped edge, from back to the front, keeping the hairline intact.

\section{LOW SUSPENSION VERSUS HIGH SUSPENSION}

Patients often simulate the effects they wish to obtain in front of the bathroom mirror by manually pressing up the droopy skin, fat compartments and SMAS [Figure 10].

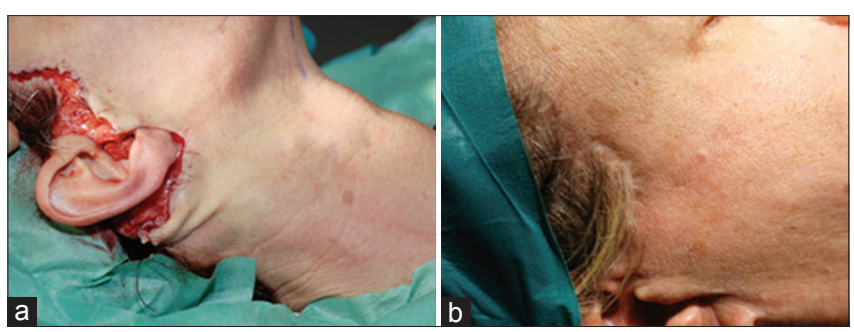

Figure 7: (a) Revision of a previous minimal access cranial suspension lift prompted scar revision. An extension in the sideburn area was of particular concern to the patient. This long incision provides ample exposure and is certainly more comfortable for the surgeon; (b) the presideburn extension of the "short scar" minimal access cranial suspension lift incision can produce a visible scar. The incisions are altogether as long as those of the classic approach with retroauricular (invisible) extensions

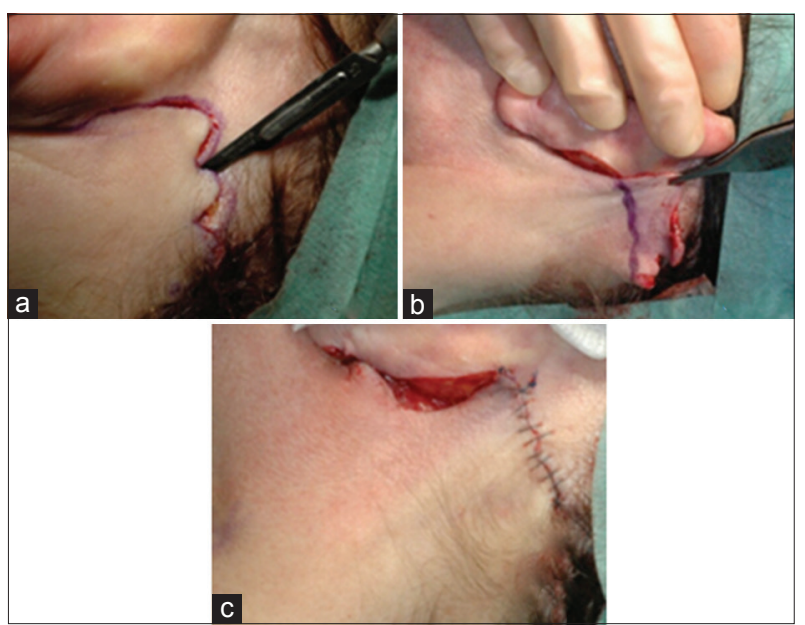

Figure 9: The scalloped incision described by Camirand and Doucet deals with the retroauricular dog-ear in an efficient way. Suturing is performed from back to the front to prevent hairline displacement, avoiding folds in the lower part of the retroauricular skin flap. (a) Scalloped design; (b) straight excision; (c) the longer straight lower margin now fits into the scallops of the upper margin
The 3 (sometimes 2 or 4 ) low suture suspension loops and 3 high suspension sutures are made of the resorbable material. The loops are woven in the SMAS layer and provide a mild purse string action that should be taken into clinical consideration [Video 5].

The inferior low reaching suspension suture picks up the posterior edge of the platysma at a point $1.5 \mathrm{~cm}$ anterior to the SCM muscle and $3 \mathrm{~cm}$ below the mandibular border, where the sliding plane between the platysma and deep cervical structures ${ }^{[21]}$ allows lifting without dissection [Figure 11]. ${ }^{[22]}$ Labbé et al. ${ }^{[22]}$ suspend the platysma and SMAS to the temporoparotid fascia described by Lore, ${ }^{[23]}$ which is located immediately in the front of the intertragal incisura and at least $2 \mathrm{~cm}$ from the facial nerve trunk. ${ }^{[24]}$ The fascia is a highly resistant point of anchorage for the 2-0 polydioxanone (PDS) suspension suture. In heavy patients, the purse string plication of the platysma and SMAS obliterates the interval between the posterior mandibular border and SCM muscle, an aesthetically important zone [Figure 12]. The author proposes that a suspension suture be placed under the SCM muscle

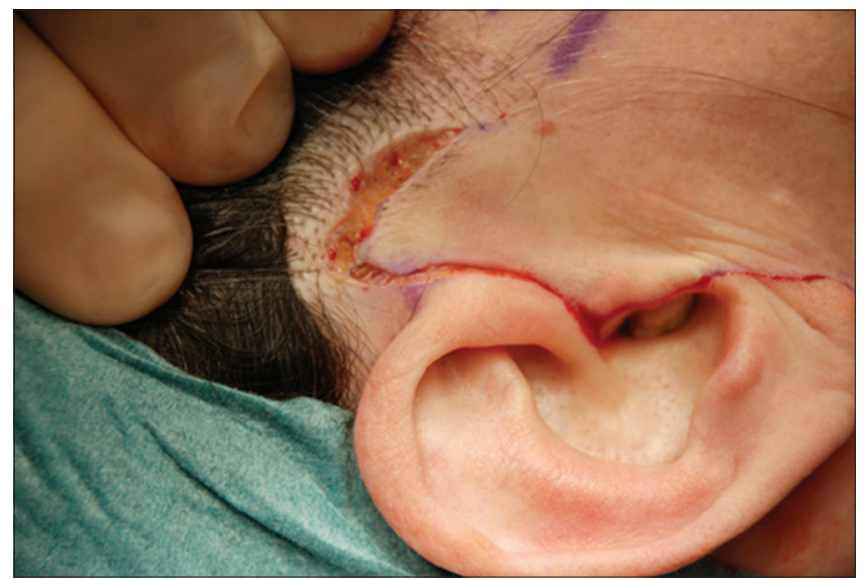

Figure 8: The infra-sideburn technique described by Knize involves a downward extension of the hockey stick design

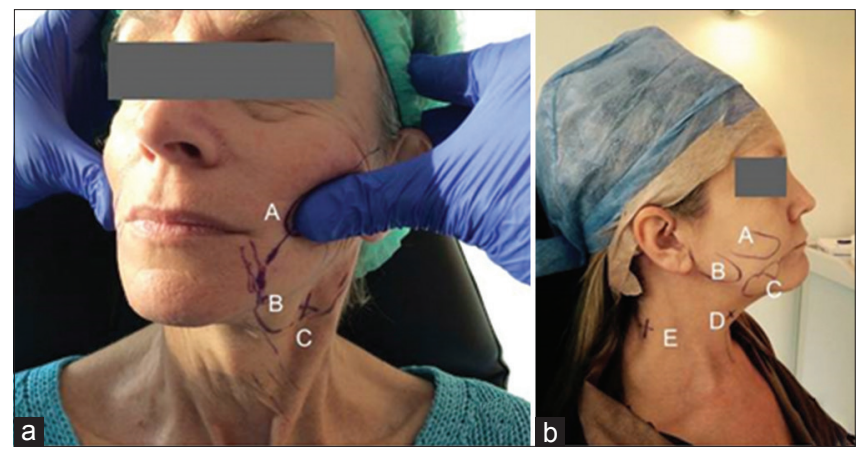

Figure 10: The position of the loops and hence the extension of the subcutaneous dissection is guided by manually simulating correction at the melolabial and mentolabial folds. The platysma is lifted after pinching it through the skin. (a) The face is lifted to undo the melolabial fold. A indicates marking around the thumb; B indicates marking at the mentolabial fold; $C$ indicates where the platysma requires elevation (marked with an "X"). Dissection extends around the markings; (b) A and $\mathrm{B}$ indicate placement of the loops that lift the melolabial and mentolabial folds. In this case, the dissection could be minimal; $\mathrm{C}$ indicates microliposuction; D indicates platysma elevation; E indicates the punctum nervosum 
to suspend the platysma to the mastoid fascia. This can be achieved by lifting the SCM muscle with one hand and sliding a mandibular awl beneath it in an anterior direction [Video 6]. The PDS suture is picked up by the awl, pulled posteriorly and knotted to the mastoid fascia using a widow needle [Figure 13]. The PDS suture requires many knots to hold. The volume and ends of the suture may cause pain when they press on the skin, such as during sleep. In addition, the ends may pierce the skin and cause painful inflammation. Suturing the surrounding tissues on the top of the knots with a 4-0 Vicryl suture can prevent this problem.

The 2-0 PDS purse string suture that is woven into the SMAS and picks up the remaining fat in the jowl area is suspended to the temporoparotid fascia described by Lore. The same procedure is used for the 2-0 PDS suture loops picking up the lower side of the nasolabial fold, which smooth the nasolabial groove and provide a moderate lift to the malar prominence. However, this effect does not appear to be maintained over time.

The high suspension is achieved by suturing the dermis in the pretragal area down to the parotid fascia using 4-0 Vicryl, with one stitch above and one stitch below the level of the tragus. Another useful high suspension maneuver was demonstrated by Dr. Heinz Bull at during the 2006 meeting of the German Association for Aesthetic Surgery in Diisseldorf. Using this technique, the skin flap is fixed to the conchal cartilage under the earlobe to prevent a pixie ear deformity. The 4-0 Vicryl includes tissue from both the dermis and the cartilage [Figure 14].

In regard to low suspension sutures, Hoefflin ${ }^{[25]}$ observed that "pulling on the SMAS is like repositioning a living room sofa by pulling on the carpet. It's easier to just pick up the sofa and position it where you want it". The
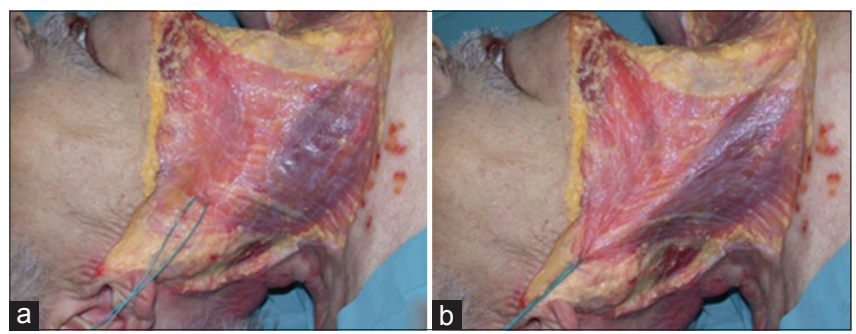

Figure 11: The platysma is more mobile a few centimeters in front of the sternocleidomastoid muscle than directly on top of it.|21] (a) Prior to elevating the platysma with the suture loop; (b) after sliding the platysma along the superficial layer of the deep cervical fascia. Courtesy of Dr. Daniel Labbé, Caen, France

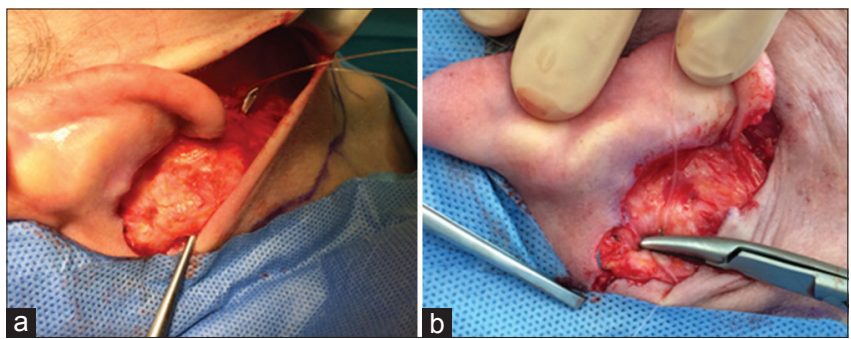

Figure 13: Platysma suspension. (a) A mandibular awl is used to lift the platysma under the sternocleidomastoid muscle; (b) suspension at the mastoid periosteum procedure described herein can therefore, be considered to be a repositioning of both the SMAS and fat.

The so-called "short scar" SMAS lift, ${ }^{[19]}$ with a strictly vertical vector, is not so short. The scar is quite long because it requires an extra skin excision in the lower eyelid [Figure 15a and c] and vertical pleating in the neck [Figure 15b] with difficult undermining in the retroauricular area and an extra posterior hairline incision. The total length of these "short scar" incisions averages $13 \mathrm{~cm}$, whereas the currently proposed procedure uses an incision with an average length of $11 \mathrm{~cm}$.

\section{MAINTAINING TRAGUS AND EARLOBE POSITION}

Trimming of the preauricular skin should be conservative because the pretragal high suture suspension creates tension on the tragal cartilage via the SMAS. Visibility of the external auditory canal is not aesthetically pleasing. The dermis overlying the tragal cartilage is trimmed over $1.5 \mathrm{~cm}$ to recreate the pretragal groove [Figure 16]. Otherwise, the flat appearance of the surface in front of

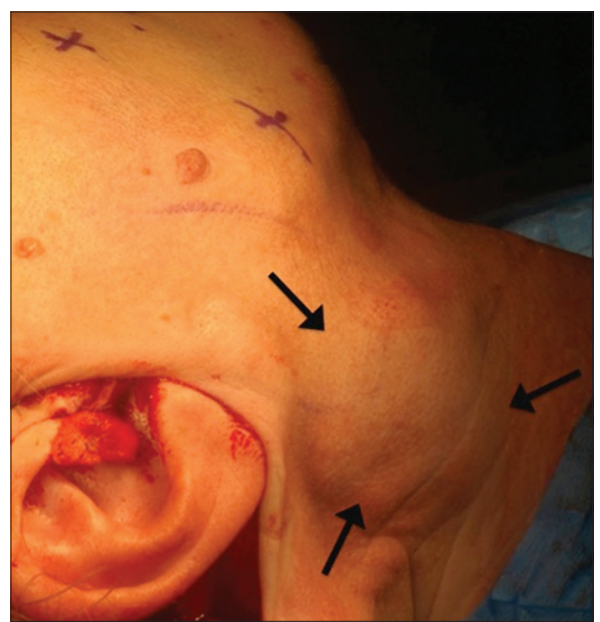

Figure 12: When sutured at the temporoparotid fascia as described by Lore, the platysma and subcutaneous fat bulge in the superolateral esthetic zone

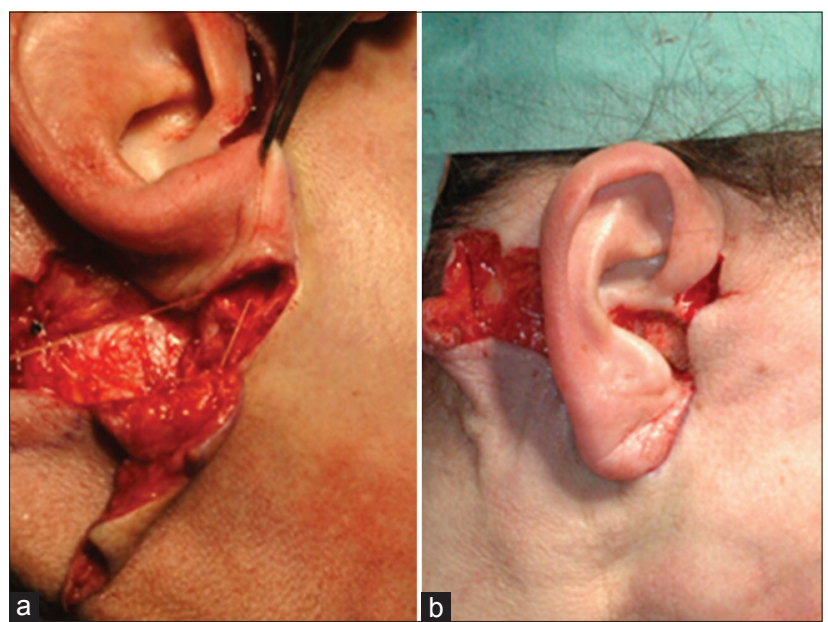

Figure 14: Suspension of the skin flap to the ear. (a) High suspension of dermis to the conchal cartilage using a 4-0 Vicryl suture; (b) the earlobe is pushed upward and backward 


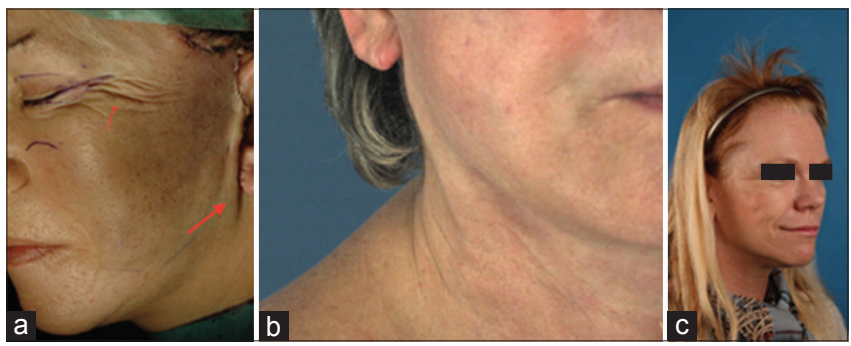

Figure 15: Complications of the vertical vector lift. ${ }^{[19]}$ (a) Vertical pleating (large arrow) and lower eyelid skin excess (small arrow). The latter is corrected by pinch blepharoplasty, which requires a 2-cm incision; (b) patient treated alio loco, presenting with vertical pleating in the neck; (c) patient treated alio loco presenting with excess skin in the lower eyelid

the tragus can indicate that a facelift has been performed. In men, the hair follicles should be meticulously trimmed, taking into consideration the desired sideburn shape and the fact that shaving the tragus (and under the earlobe) is a nuisance and may lead to repeated bleeding. Two 4-0 Vicryl sutures in this location will support lifting and shaping of the pretragal fovea.

Trimming under the earlobe should also be conservative. The anterior skin flap created during the resection of excess skin can usually be pulled behind the earlobe to determine how much needs to be resected. Because the earlobe will be pulled forward and downward by gravity and collagen contraction during the first few weeks following surgery, the shape of the skin flap should push the earlobe upward and backward [Figure 14].

Skin closure with 5-0 nylon starts at the superior end of the incision and continues down to the earlobe, stopping behind the earlobe and repositioning it upward and backward.

\section{FIBRIN GLUE}

The use of vacuum drains and extensive bandaging is not recommended. Fibrin glue spray is preferred to prevent hematomas, ecchymosis, seromas and discharge [Video 7]. The sealant should be applied while the wound is still open $(0.5 \mathrm{~mL}$ each side) to allow air to escape and prevent venous air embolism. The wound bed is dried by introducing a suction drain connected to the central vacuum system under the skin flap before skin suturing.

\section{LIP AND EARLOBE REDUCTION}

Whereas a turkey gobbler neck and lower eyelid bags are spotted quickly and addressed with blepharoplasty and liposuction, long upper lips and earlobes are often overlooked. ${ }^{[26]} \mathrm{A}$ long upper lip (and low lower lip) expose the lower teeth when smiling, a typical sign of aging. Pendulous earlobes can result from wearing heavy jewelry over many decades.

Upper lip reduction and nasal tip lift are accomplished by a modification ${ }^{[27]}$ of the "double duck" procedure, ${ }^{[28]}$ which is a modification of Austin ${ }^{[26]}$ sub-nasal buffalo horn excision. This procedure involves a sub-alar

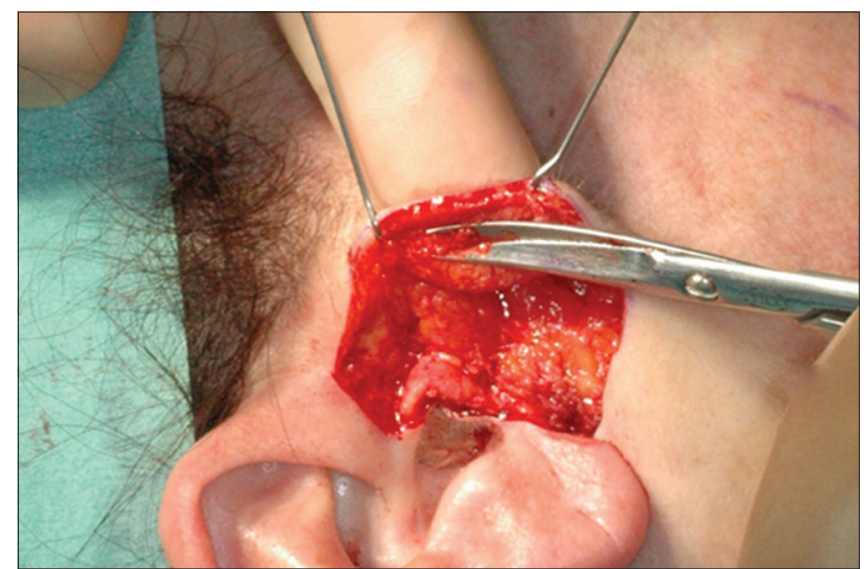

Figure 16: Creating the pretragal fovea. Trimming the flap to the dermis

crescent-shaped skin excision which continues into the membranous septum and which may be reduced in height if the nasolabial angle requires sharpening and a hanging columella is present. Otherwise, a full transfixion incision divides the medial crural footplates and the caudal septum. The dermis of the central lip is then suspended to it with a 4-0 PDS suture. The columella can then slide upward slightly with the footplates for the elevation of the nasal tip [Figure 17].

Earlobe reduction can be performed with marginal excision and fine sutures, although removal of a full-thickness medially based wedge produces better results. The facial skin flap is pulled up behind the newly formed earlobe to allow for proper cephalad repositioning [Figures 18 and 19].

\section{Recommended sequence}

- Premedicate

- Mark locations of the suspension loops and extent of dissection

- Secure intravenous access

- Prep and drape

- Mark incision lines

- Intravenous sedation

- Infiltrate of local anesthetic in the anterior neck for submental liposuction

- Perform submental liposuction

- Perform nerve block anesthesia and infiltrate local an esthetic

- Perform liposuction of jowl

- Incise and elevate pre-and post-auricular flaps and connect pockets

- Perform lateral SMAS ectomy

- Weave suspension sutures into the nasolabial fold, jowl area and platysma

- Fixate platysma to the substernomastoid region with a 2-0 PDS suture, followed by over-suturing with 4-0 Vicryl suture

- Knot the remaining suspension sutures onto the temporoparotid fascia, as described by Lore $^{[23]}$

- Mark and excise of excess skin in the preauricular region

- Trim pretragal subcutaneous sutures, and place high suspension suture to shape the pretragal fovea and drape the skin 


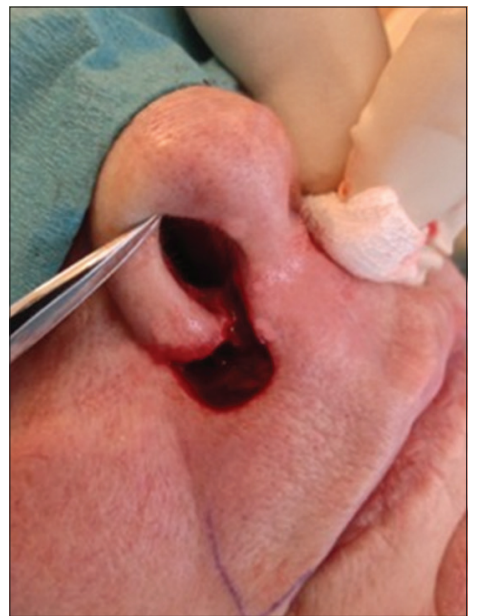

Figure 17: The "double duck" procedure with full transfixion incision lifts the nasal tip and can correct a hanging columella by resection of the membranous septum

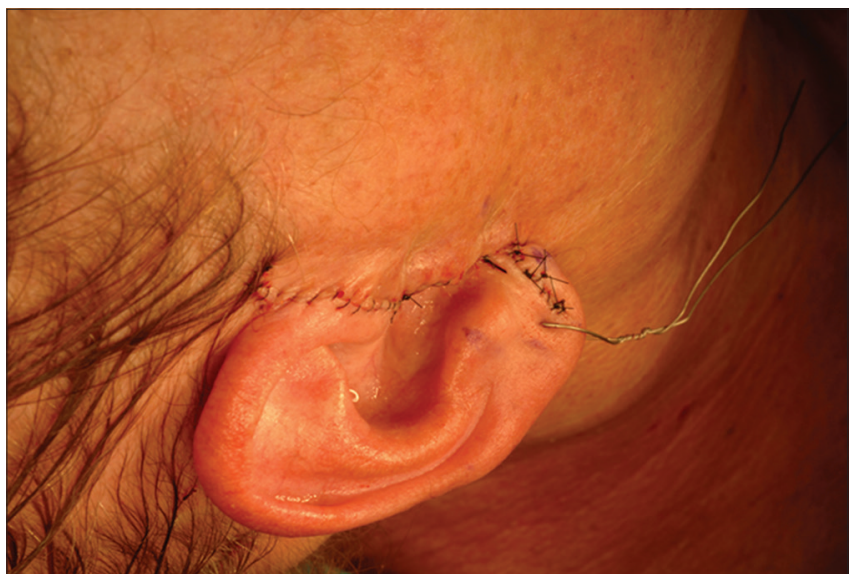

Figure 18: Earlobe reduction. Triangular excision and upward rotation of the lower earlobe flap. Suturing is performed, and a new perforation allows for secondary epithelialization on a $0.4 \mathrm{~mm}$ titanium wire (cut short at the end)

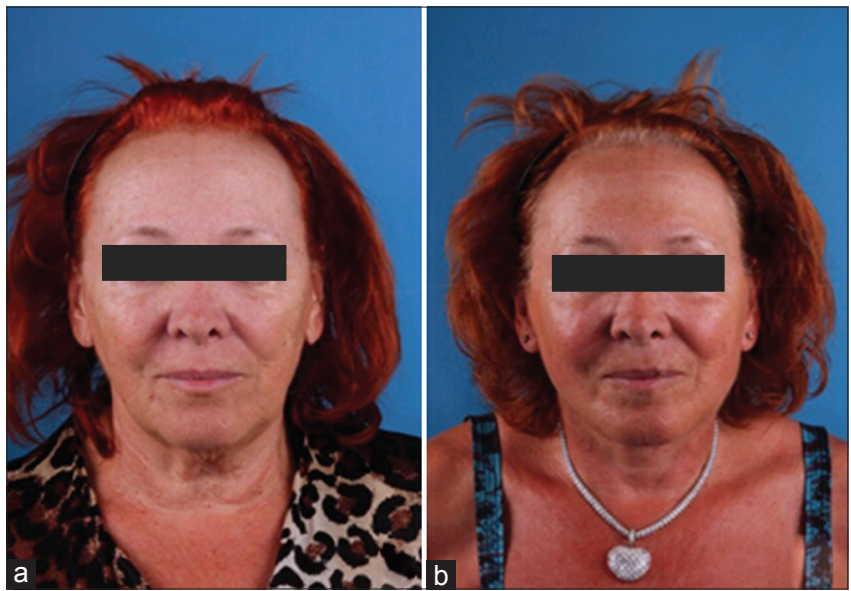

Figure 19: (a) Before buccocervical lift and earlobe reduction; (b) six months after the procedures

- Suspend the dermis to the conchal cartilage

- Place a Redon drain under the skin flap

- Suture the preauricular skin

- Excise excess postauricular skin

- Place high suspension suture to drape the postauricular flap provisionally
- Remove the Redon drain and apply fibrin glue spray

- Suture the postauricular skin

- Apply a pressure dressing with gauze behind the earlobes.

\section{Products required}

Xylonor $(30 \mathrm{mg} / \mathrm{mL})+0.04 \mathrm{mg} / \mathrm{mL}$ noradrenaline $1.8 \mathrm{~mL}$ (Septodont, Saint-Maur-des-Fossés, France).

\section{Declaration of patient consent}

The authors certify that they have obtained all appropriate patient consent forms. In the form the patient(s) has/have given his/her/their consent for his/her/their images and other clinical information to be reported in the journal. The patients understand that their names and initials will not be published and due efforts will be made to conceal their identity, but anonymity cannot be guaranteed.

\section{Financial support and sponsorship} Nil.

\section{Conflicts of interest}

There are no conflicts of interest.

\section{REFERENCES}

I. Rafaty FM, Brennan HG. Curent concepts of browpexy. Arch Otolaryngol 1983;109:152-4.

2. Mommaerts MY, Abeloos JS, De Clercq CA, Neyt LF. Brow and forehead lift with cranial suspension. Technical note. J Craniomaxillofac Surg 1994;22:33-6.

3. Isse BG. Endoscopic facial rejuvenation: endoforehead, the functional lift. Case reports. Aesthetic Plast Surg 1994; 18:21-9.

4. Fogli AL. Temporal lift by galeapexy. A review of 270 cases. Aesthetic Plast Surg 2003;27:159-65.

5. Knize DM. The Forehead and Temporal Fossa. Philadelphia: Lippincott Williams and Wilkins; 200I.

6. Stevens WG, Apfelberg DB, Stoker DA, Schantz SA. The endotine: a new biodegradable fixation device for endoscopic forehead lifts. Aesthet Surg J 2003;23:103-7.

7. Lam S, Glassgold MJ, Glasgold RA. Complementary Fat Grafting. Philadelphia: Lippincott, Williams and Wilkins; 2006.

8. Altman K. Facial feminization surgery: current state of the art. Int J Oral Maxillofac Surg 2012;41:885-94.

9. Wan D, Amirlak B, Rohrich R, Davis K. The clinical importance of the fat compartments in midfacial aging. Plast Reconstr Surg Glob Open 20 I4; I:e92.

I0. Geissler PJ, Davis K, Roostaeian J, Unger J, Huang J, Rohrich RJ. Improving fat transfer viability: the role of aging, body mass index, and harvest site. Plast Reconstr Surg 2014;134:227-32.

II. Carruthers JD, Fagien S, Rohrich RJ, Weinkle S, Carruthers A. Blindness caused by cosmetic filler injection: a review of cause and therapy. Plast Reconstr Surg 2014;134:1 197-201.

12. Greenblatt DJ, Shader RI, Franke K, Maclaughlin DS, Harmatz JS, Allen MD, Werner A, Woo E. Pharmacokinetics and bioavailability of intravenous, intramuscular, and oral lorazepam in humans. J Pharm Sci 1999;68:57-63.

13. KantoJH. Midazolam: the first water-soluble benzodiazepine. Pharmacology, pharmacokinetics and efficacy in insomnia and anesthesia. Pharmacotherapy 1985;5:138-55.

14. Ramsay MA, Savege TM, Simpson BR, Goodwin R. Controlled sedation with alphaxalone-alphadolone. Br Med J 1974;2:656-9.

15. Klein JA. Anesthetic formulation of tumescent solutions. Dermatol Clin 1999; 17:751-9.

16. Baker D. Rhytidectomy with lateral SMASectomy. Facial Plast Surg 2000;16:209-13.

17. Frechet P. Minimal scars for scalp surgery. Dermatol Surg 2007;33:45-55

18. Camirand A, Doucet J. A comparison between parallel hairline incisions and perpendicular incisions when performing a face lift. Plast Reconstr Surg 1997;99:10-15.

19. Tonnard P, Verpaele A. Short-scar Face Lift. Operative Strategies and Techniques. St. Louis: Quality Medical Publishing; 2007. 
20. Knize DM. Periauricularface lift incisions and the auricular anchor. Plast Reconstr Surg 1999; 104:1508-20.

21. Gardetto A, Dabernig J, Rainer C, Piegger J, Piza-Katzer H, Fritsch H. Does a superficial musculoaponeurotic system exist in the face and neck? An anatomical study by the tissue plastination technique. Plast Reconstr Surg 2003; I I 1:664-72.

22. Labbé D, Franco RG, Nicolas J. Platysma suspension and platysmaplasty during neck lift: anatomical study and analysis of 30 cases. Plast Reconstr Surg 2006; I 17:200I-7.

23. Lore JM. An Atlas of Head and Neck Surgery. 2nd ed. Philadelphia: Saunders; 1973.
24. O'Brien JX, Rozen WM, Whitaker IS, Ashton MW. Lore's fascia and the platysma-auricular ligament are distinct structures. J Plast Reconstr Aesthet Surg 20I2;65:e24I-5.

25. Hoefflin S. Facial rejuvenation-my personal evolution. Aesthet Surg J 1998; 18:286-9.

26. Austin HW. The lip lift. Plast Reconstr Surg 1986;77:990-4.

27. Cardim VL, Salomons RL, De Faria Valle R, De Souza JO, De Lima ES. “Double duck" nasolabial lifting. Rev Bras Cir Plást 201 I;26:466-7I.

28. Mommaerts MY, editor. Lip lift. In: The Surgical Art of Facial Makeover. Planning and Operative Techniques. Vol. I. Sint-Martens-Latem: Orthoface $\mathrm{R}$ and D; 20I3. p. 29I-4. 